\title{
Avaliação da disponibilidade de informações toxicológicas de produtos químicos utilizados em larga escala no Brasil
}

\author{
Clovis Sanchez, Elizabeth de Souza Nascimento* \\ Departamento de Análises Clínicas e Toxicológicas, Faculdade de Ciências Farmacêuticas, Universidade de São \\ Paulo.
}

*Correspondência:

E. S. Nascimento

Departamento de Análises Clínicas e

Toxicológicas, FCF/USP

Av Lineu Prestes, 580, bloco 13B.

05389-970 - São Paulo -Brasil

e-mail:esnasci@usp.br
Este estudo teve como finalidade realizar um levantamento sobre a existência de nove tipos de informações toxicológicas sobre os produtos químicos que estão sendo utilizados no Brasil, em quantidades superiores ou iguais a 500 toneladas por ano, restritos àqueles produtos cujas investigações não estão sendo feitas por entidades reconhecidas pela comunidade científica internacional, fora do Brasil. Como resultado, observou-se que na amostragem de 461 produtos químicos utilizados em larga escala no Brasil, apenas dezoito destes produtos possuíam os nove tipos de informações toxicológicas abordadas nesse estudo. Também constatou-se que doze produtos químicos não possuíam quaisquer informações toxicológicas, impossibilitando um estudo de avaliação do risco destes produtos.
Unitermos

- Avaliação do risco

- Identificação do perigo

- Produtos químicos/

informações toxicológicas

- Responsabilidade social

- Segurança química

\section{INTRODUÇÃO}

Durante o ciclo de vida de um produto químico é possível que frações desse produto ou de seus precursores alcancem os compartimentos ambientais, gerando riscos às riquezas naturais e à saúde das populações presentes nesses compartimentos.

Uma vez que existe o risco é imprescindível investigálo, a fim de estabelecer, quando necessário, medidas preventivas e emergenciais visando à proteção do meio ambiente, da saúde humana e das demais espécies presentes no planeta.

O processo utilizado pela comunidade científica para realizar investigações sobre a capacidade de um produto químico causar danos é conhecido como avaliação do risco. Esse processo permite realizar uma caracterização científica e sistemática do potencial de efeitos adversos à saúde, resultantes de uma ou mais exposições aos produtos químicos causadores desses efeitos (Faustmam, Omenn, 1996).
Entre as metodologias mais conhecidas e utilizadas no mundo para avaliação do risco de produtos químicos estão as da Organização para a Cooperação Econômica e Desenvolvimento (OECD). Desde a década de 1980, essa entidade vem publicando diversos métodos aprovados pela comunidade científica internacional, com o intuito de padronizar e promover a segurança química mundial (OECD, 2000).

Apesar desse paradigma existir há mais de vinte anos, um estudo realizado em 1997 pelo Fundo de Defesa Ambiental - EDF (entidade não governamental com sede nos Estados Unidos) revelou que muitos produtos químicos fabricados em larga escala naquele país ainda não possuíam um conjunto de informações toxicológicas básicas que permitissem avaliar seus riscos (EDF, 1997; ICF, 1998; EPA, 2000).

Após o estudo da EDF, reconhecendo a falta de informações toxicológicas e a urgência para a obtenção dessas informações, muitas instituições governamentais e não-governamentais estabeleceram programas específi- 
cos visando obtê-las. Como exemplos desses programas podem ser citados: o da Agência de Proteção Ambiental dos Estados Unidos, que tornou obrigatório naquele país o levantamento de dados toxicológicos de mais de 2500 produtos químicos; o do Conselho Internacional das Associações Químicas, que está trabalhando no levantamento de dados toxicológicos de uma lista inicial de mais de 1000 produtos químicos, e o da Organização para a Cooperação Econômica e Desenvolvimento, cuja lista de produtos químicos a investigar conta com mais de 6000 itens (EPA, 1999, 2000; OECD, 2000; ICCA, 2001).

Quanto ao Brasil, não existe até o momento um programa governamental voltado para a obtenção das informações toxicológicas de todos os produtos químicos utilizados no país, embora tenha assumido com o Fórum Intergovernamental de Segurança Química das Nações Unidas, em 2000, o compromisso de obter os dados mínimos necessários à identificação dos perigos associados às substâncias químicas fabricadas em seu território (IFCS, 2000; BRASIL, 2001).

Assim, para iniciar um trabalho, no Brasil, nos moldes dos programas já existentes torna-se necessário e urgente realizar um levantamento das informações toxicológicas que deveriam ser implementadas para os produtos químicos utilizados no território brasileiro.

Nessa perspectiva, o presente trabalho visou pesquisar a existência de informações toxicológicas dos produtos químicos que estão sendo utilizados no Brasil, em quantidades iguais ou superiores a 500 toneladas por ano, que se caracterizam como HPV (High Production Volu$m e)$, restritos àqueles produtos cujas investigações não estão sendo feitas por entidades reconhecidas pela comunidade científica internacional, fora do Brasil.

\section{Etapas da pesquisa}

Foram determinadas as seguintes etapas para a pesquisa:

$1^{\text {a }}$ Etapa: Escolha das informações a serem pesquisadas;

$2^{\text {a }}$ Etapa: Definição de critérios para a pesquisa;

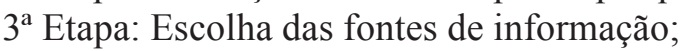

$4^{\mathrm{a}}$ Etapa: Pesquisa das informações nas fontes escolhidas, de acordo com os critérios definidos.

\section{RESULTADOS E DISCUSSÃO}

\section{1'- Etapa: Escolha das informações a serem pesquisadas}

Foram escolhidas as informações mínimas necessárias para permitir a seleção dos produtos químicos que atendessem os objetivos desse trabalho e um con- junto de informações sobre os dados toxicológicos mais utilizados em estudos de avaliação do risco de produto químicos. Essas informações foram:

Para a seleção dos produtos químicos: nome do produto químico; número do produto no Chemical Abstract System (CAS); capacidade instalada de fabricação do produto no país; quantidade da produção nacional; quantidade da importação; principais aplicações do produto químico; e nome das instituições que estão desenvolvendo ou já possuem estudos sobre os produtos químicos utilizados no Brasil.

Para o estudo da existência de informação toxicológica: toxicidade aguda, toxicidade crônica, genotoxicidade, efeitos adversos à reprodução e/ou teratogenicidade, ecotoxicidade, capacidade de fotodegradação, capacidade de hidrólise, transporte e distribuição dos produtos químicos em compartimentos ambientais; e biodegradação.

\section{2ªpa: Definição de critérios para a pesquisa}

Os critérios básicos para a seleção do produto químico visando utilizá-lo nesse estudo foram:

- a possibilidade de associação da nomenclatura do produto químico encontrado na fonte pesquisada, com um número $C A S$;

- a indicação de que esse produto químico foi produzido ou importado pelo Brasil, em quantidades superiores a 500 toneladas por ano;

- a não participação do produto químico nos programas de investigações toxicológicas da USEPA, ICCA, $O E C D$ ou outro indicado por essas instituições;

- a inexistência de um relatório com informações toxicológicas sobre o produto químico, no guia de referência publicado pela $U N E P$ e;

- a informação estar disponível ao público, porém atendendo aos critérios citados anteriormente.

Os critérios básicos para aceitação da existência de cada uma das informações toxicológicas pesquisadas nesse estudo foram:

- sempre que a fonte consultada continha, pelo menos, um dado sobre a informação toxicológica pesquisada, sem avaliar a qualidade da informação disponível na fonte e;

- a disponibilidade pública da informação.

\section{3a Etapa: Escolha das fontes de informação}

Para a seleção dos produtos, foram escolhidas duas fontes, oriundas do setor químico brasileiro, por serem as mais completas, atualizadas e que estavam disponíveis ao 
público, no momento da pesquisa. Também foi escolhida uma fonte do Ministério da Indústria e Comércio Exterior, por trazer referências de todos os produtos químicos importados pelo Brasil (ABIQUIM, 2000; ANUÁRIO, 2000; GUIA, 2001, 2005; MINISTÉRIO, 2001).

Para a obtenção do número do produto no Chemical Abstract System (CAS), foram selecionadas as fontes, onde era possível realizar a pesquisa por intermédio da nomenclatura oficial, de sinônimos ou nomes comerciais dos produtos químicos.

Para a pesquisa das informações toxicológicas, foram selecionadas as fontes encontradas no site da Biblioteca Nacional de Medicina, dos Estados Unidos da América, por serem acessíveis ao público e por terem sido utilizadas pela USEPA em programa de investigação da existência de dados toxicológicos naquele país. Além dessas, foram também utilizadas outras fontes de informações indicadas na Tabela I.

\section{4- Etapa: Pesquisa das informações nas fontes escolhidas, de acordo com os critérios definidos}

Durante a pesquisa para selecionar os produtos químicos a serem utilizados neste estudo, foi constatado que grande parte da nomenclatura dos produtos não estava de acordo com as regras preconizadas pela comunidade científica internacional, nem utilizava critérios para possibilitar uma identificação inequívoca (IUPAC, 2002) (Tabela II). Isso impossibilitou associar alguns produtos químicos inscritos nas fontes, com o seu respectivo número $C A S$.

Sobre a pesquisa relativa aos dados de produção para selecionar quais os produtos químicos utilizados em larga escala no país, foi possível observar que:

- $80,04 \%$ dos 461 produtos químicos selecionados para este estudo possuíam capacidade instalada de fabricação, ou seja, existiam locais de produção no Brasil. Em conclusão, 19,96\% desses produtos foram, obrigatoriamente, importados pelo país no período abrangido no estudo. Essas observações tornam-se importantes, pois ao reconhecer a capacidade de produção no país, mesmo existindo produtores em outros países, deve-se considerar a responsabilidade pela avaliação dos riscos daquilo que o Brasil produz. Por outro lado, quando um produto químico não é produzido em um país, as informações toxicológicas desse produto podem ser exigidas daquele que o produziu, restando aos usuários, a utilização dessas informações para a promoção da segurança química no país.

- $63,77 \%$ dos 461 produtos químicos selecionados para este estudo possuíam dados comprovados de fabricação ou importação para o Brasil. Essa informação é importante, principalmente para estudos epidemiológicos onde se relacionam efeitos tóxicos com períodos de utilização do produto na região

A Tabela III apresenta a distribuição do número e percentual dos produtos químicos associados a um número $C A S$, segundo suas participações nos programas voltados para a avaliação de risco da $O E C D, I C C A$ e USEPA e UNEP.

Com relação à participação dos produtos em programas já existentes, voltados para a avaliação do risco:

- Dos 461 produtos químicos selecionados para este estudo $2,83 \%$ estão tendo seus dados toxicológicos desenvolvidos por um programa específico, no âmbito da $O E C D$. Embora o Brasil não seja membro dessa organização, ele poderá ser beneficiado com o acesso às informações geradas pelo programa, pois os resultados dos estudos serão divulgados pela UNEP.

- A indústria química instalada no Brasil poderia participar da geração dos dados toxicológicos de $42,08 \%$ dos 461 produtos químicos selecionados para este estudo, já que um dos seus representantes no país tem assento no ICCA. Com isto, essa indústria poderia dividir com outros países os custos dos estudos, além de aumentar as chances de aceitação dos resultados dos estudos que venha a desenvolver isoladamente. Contudo, o Brasil também deverá se beneficiar com o acesso às informações geradas pelo programa do ICCA, pois os resultados dos estudos deverão ser divulgados pela $U N E P$, com o apoio da $O E C D$.

- Apenas 3,90\% dos 461 produtos químicos selecionados possuíam, em 2001, os nove tipos de informações toxicológicas pesquisadas por este estudo, sendo que estas informações estão disponíveis ao público, por intermédio do Órgão das Nações Unidas para a Proteção Ambiental - UNEP (UNEP 2001). É importante mencionar que em julho de 2005, a quantidade de publicações da UNEP sobre dados toxicológicos dos 461 produtos químicos indicados na tabela III havia subido de 18 para 55 publicações (UNEP 2005). Isso representou, para o presente estudo, um aumento de 3,9\% para $10,9 \%$ de produtos químicos com informações toxicológicas básicas, em um período de 4 anos.

- Cento e cinquenta dos 461 produtos químicos selecionados inicialmente para este estudo não tinham seus potenciais toxicológicos investigados pelos programas da $O E C D$, USEPA ou ICCA. Isso sugere que caso estas informações não existam, elas deveriam ser obtidas em outros fóruns, uma vez que sem essas não seria possível desenvolver programas de segurança química para esses produtos. Por esse motivo, esses 150 produtos passaram a ser o objeto de investigação neste estudo. 
TABELA I - Fontes de informação escolhidas para o estudo da disponibilidade de informações toxicológicas de produtos químicos utilizados em larga escala no Brasil

\begin{tabular}{|c|c|c|}
\hline & DADOS A SEREM COLETADOS & FONTES DE INFORMAÇÃO \\
\hline 1 & Nome do produto químico, em português & $\begin{array}{l}\text { (ANUÁRIO DA INDÚSTRIA QUÍMICA, 2000; } \\
\text { GUIA DA INDÚSTRIA QUÍMICA, 2000/2001, } \\
\text { 2005; MDIC, 2001) }\end{array}$ \\
\hline 2 & $\begin{array}{l}\text { Nome do produto químico, em inglês, e os } \\
\text { respectivos sinônimos }\end{array}$ & $\begin{array}{l}\text { (ANUÁRIO DA INDÚSTRIA QUÍMICA, } \\
\text { 2000, 2005; CIS, 1999; CORNELL, 2002; DHHS, } \\
\text { 2001; GUIA DA INDÚSTRIA QUÍMICA, 2000/ } \\
\text { 2001; ILO, 2000; LEWIS, R. J., 1997; MERCK, 1996; } \\
\text { MSDS, 2001; NLM, 1998a; SIGMA 1998, 1999; SIRI, } \\
\text { 2002; UNEP, 2001; WHO, 2002) }\end{array}$ \\
\hline 3 & Número $C A S$ & $\begin{array}{l}\text { (CIS, 1999); CORNELL, 2002; DHHS, 2001; ILO, } \\
\text { 2000; LEWIS, R. J., 1997; MERCK, 1996; MSDS, } \\
\text { 2001; NLM, 1998a; (SIGMA 1998, 1999); (SIRI, } \\
\text { 2002; UNEP, 2001; WHO, 2002) }\end{array}$ \\
\hline 4 & Capacidade instalada no País & $\begin{array}{l}\text { (ANUÁRIO DA INDÚSTRIA QUÍMICA, 2000; } \\
\text { GUIA DA INDÚSTRIA QUÍMICA, 2000/2001) }\end{array}$ \\
\hline 5 & Produção nacional & (ANUÁRIO DA INDÚSTRIA QUÍMICA, 2000) \\
\hline 6 & Importação & $\begin{array}{l}\text { (ANUÁRIO DA INDÚSTRIA QUÍMICA, 2000; } \\
\text { MDIC, 2001; RELATÓRIO SDI, 1999) }\end{array}$ \\
\hline 7 & Principais aplicações do produto químico & $\begin{array}{l}\text { (GUIA DA INDÚSTRIA QUÍMICA, 2000/2001; } \\
\text { LEWIS, R. J., 1997; MERCK, 1996) }\end{array}$ \\
\hline 8 & $\begin{array}{l}\text { Nome da(s) fonte(s) de informação que } \\
\text { contenham dados sobre a toxicidade aguda } \\
\text { de cada produto químico }\end{array}$ & $\begin{array}{l}\text { RTECS (NLM, 1998b); TSCATS (SYRACUSE, } \\
\text { 1998a, 2005) }\end{array}$ \\
\hline 9 & $\begin{array}{l}\text { Nome da(s) fonte(s) de informação que } \\
\text { contenham dados sobre a toxicidade } \\
\text { crônica de cada produto químico }\end{array}$ & $\begin{array}{l}\text { IRIS (NLM, 1998d, 2005); TSCATS (SYRACUSE, } \\
\text { 1998a, 2005) }\end{array}$ \\
\hline 10 & $\begin{array}{l}\text { Nome da(s) fonte(s) de informação que } \\
\text { contenham dados sobre a } \\
\text { genotoxicidade de cada produto químico }\end{array}$ & $\begin{array}{l}\text { CCRIS (NLM, 1998e, 2005); EMIC (NLM, 1998g, } \\
\text { 2005); GENE-TOX (NLM, 1998f, 2005); IRIS (NLM, } \\
\text { 1998d, 2005); RTECS (NLM, 1998b, 2005); TSCATS } \\
\text { (SYRACUSE, 1998a, 2005) }\end{array}$ \\
\hline 11 & $\begin{array}{l}\text { Nome da(s) fonte(s) de informação que contenham } \\
\text { dados sobre os efeitos adversos à reprodução } \\
\text { e teratogenicidade de cada produto químico }\end{array}$ & $\begin{array}{l}\text { ETIC (NLM, 1998h, 2005); RTECS (NLM, 1998b); } \\
\text { TSCATS (SYRACUSE, 1998a, 2005) }\end{array}$ \\
\hline 12 & $\begin{array}{l}\text { Nome da(s) fonte(s) de informação que contenham } \\
\text { dados sobre a ecotoxicidade de cada produto químico. }\end{array}$ & $\begin{array}{l}\text { AQUIRE (EPA, 1998d, 2005); TSCATS } \\
\text { (SYRACUSE, 1998a, 2005) }\end{array}$ \\
\hline 13 & $\begin{array}{l}\text { Nome da(s) fonte(s) de informação que contenham } \\
\text { dados sobre capacidade de fotodegradação } \\
\text { de cada produto químico }\end{array}$ & $\begin{array}{l}\text { CHEMFATE (SYRACUSE, 1998d); TSCATS } \\
\text { (SYRACUSE, 1998a) }\end{array}$ \\
\hline 14 & $\begin{array}{l}\text { Nome da(s) fonte(s) de informação que contenham } \\
\text { dados sobre a capacidade de } \\
\text { hidrólise de cada produto químico }\end{array}$ & $\begin{array}{l}\text { CHEMFATE (SYRACUSE, 1998b, 2005); } \\
\text { DATALOG (SYRACUSE, 1998d, 2005); } \\
\text { TSCATS (SYRACUSE, 1998a, 2005) }\end{array}$ \\
\hline 15 & $\begin{array}{l}\text { Nome da(s) fonte(s) de informação que contenham } \\
\text { dados sobre o transporte e distribuição dos produtos } \\
\text { químicos em compartimentos ambientais } \\
\text { de cada produto químico }\end{array}$ & TSCATS (SYRACUSE, 1998a, 2005) \\
\hline
\end{tabular}


TABELA I - continuação.

\begin{tabular}{|c|c|c|}
\hline & DADOS A SEREM COLETADOS & FONTES DE INFORMAÇÃO \\
\hline 16 & $\begin{array}{l}\text { Nome da(s) fonte(s) de informação que contenham } \\
\text { dados sobre capacidade de biodegradação } \\
\text { de cada produto químico }\end{array}$ & $\begin{array}{l}\text { BIODEG (SYRACUSE, 1998e, 2005); BIOLOG } \\
\text { (SYRACUSE, 1998e, 2005); CHEMFATE } \\
\text { (SYRACUSE, 1998d, 2005); DATALOG } \\
\text { (SYRACUSE, 1998b, 2005); ENVIROFATE } \\
\text { (SYRACUSE, 1998, 2005); TSCATS (SYRACUSE, } \\
\text { 1998a, 2005) }\end{array}$ \\
\hline 17 & $\begin{array}{l}\text { Nomes das instituições que estão desenvolvendo } \\
\text { ou já possuem estudos conclusivos sobre a } \\
\text { periculosidade dos produtos químicos para o } \\
\text { homem e para o meio ambiente }\end{array}$ & $\begin{array}{l}\text { (ICCA, 1999); (EPA, 1998b) (UNEP, 2001); } \\
\text { (OECD; 2000b, 2005) }\end{array}$ \\
\hline
\end{tabular}

TABELA II - Distribuição do número e percentual dos produtos químicos utilizados como base para compor o inventário, segundo sucesso de associação com um número $C A S$

\begin{tabular}{lcc}
\hline $\begin{array}{l}\text { Sucesso de associação } \\
\text { com um número }\end{array}$ & CAS & $(\%)$ \\
\hline Sim & 461 & 43,53 \\
Não & 598 & 56,47 \\
Total & 1.059 & 100,00 \\
\hline
\end{tabular}

Fonte: Anuário e Guia da Indústria Química, 1999 e 2000

TABELA III - Distribuição do número e percentual dos produtos químicos associados a um número $C A S$, segundo suas participações nos programas voltados para a avaliação do risco da $O E C D, I C C A$ e USEPA e UNEP

\begin{tabular}{lcc}
\hline Participações em programas & $\mathrm{n}^{\circ}$ & $\%$ \\
\hline OECD & 13 & 2,83 \\
ICCA & 194 & 42,08 \\
USEPA & 28 & 6,07 \\
UNEP **) $^{*}$ Demais situações* & 18 & 3,90 \\
Sem participação & 58 & 12,58 \\
Total & 150 & 32,54 \\
\end{tabular}

(*) Produtos químicos cujas investigações toxicológicas deverão ser realizadas em outros programas, além dos referidos programas citados nesta tabela.(**) (UNEP, 2001).

Porém, em março de 2005, foram retirados da lista dos produtos selecionados para o presente estudo aqueles que passaram a ser incorporados a um dos programas de investigação toxicológica referendadas neste estudo (USEPA, ICCA ou OECD) no período de 2000 a 2005 (TabelaIV). Com isso a lista passou de 150 para 131 produtos químicos a serem analisados (OECD, 2005).
Assim, os produtos químicos abordados neste estudo passaram a ser os indicados na Tabela V.

Dentre esses produtos observa-se que:

- alguns polímeros, cujos monômeros já foram exaustivamente estudados, bem como alguns produtos químicos que já tiveram suas investigações toxicológicas desenvolvidas fora do âmbito de um programa internacional (incluindo estudos para efeito de registro no Brasil), ou ainda produtos químicos utilizados há muito tempo, sem uma indicação relevante quanto à capacidade de causarem danos toxicológicos para seus usuários, provavelmente não deverão ser alvos de estudos urgentes promovidos por empresas fabricantes, governos ou sociedade, pois não devem representar riscos eminentes de danos à saúde da população ou ao meio ambiente.

- alguns praguicidas citados na Tabela $\mathrm{V}$ já possuem algumas informações toxicológicas no IPCS, que é o programa de segurança química da Organização Mundial de Saúde e na Agency for Toxic Substances and Disease Registry (ATSDR) que é uma agência do Departamento de Saúde dos EUA (WHO, 1984, 1988, $1989,1992,1994)$. Os resultados da pesquisa referentes à existência de informações toxicológicas para os produtos selecionados são observados na Figura 1.

Nenhum dos produtos químicos possuía todas as informações toxicológicas referentes aos nove tipos pesquisados neste estudo. Além disso, doze desses produtos não possuíam nenhuma das nove informações toxicológica abordadas. A falta destas informações impede, principalmente, o estabelecimento de programas preventivos apropriados, cientificamente embasados, voltados para a segurança das populações expostas a eles e para a proteção das riquezas naturais do país.

Como exemplo, a falta de informações sobre a toxicidade aguda e crônica de um produto prejudica uma análise adequada sobre a relação dose-resposta desse pro- 


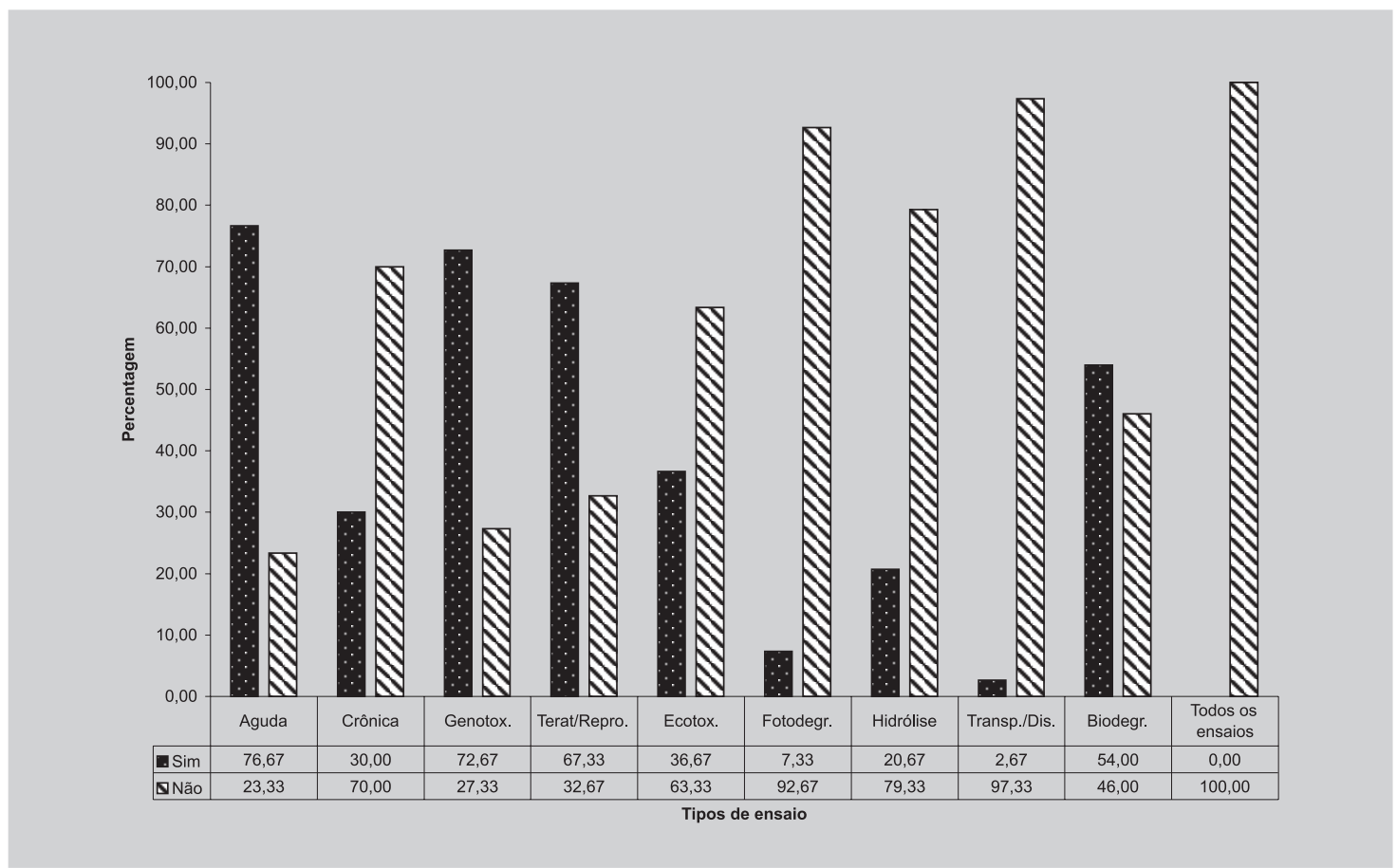

FIGURA 1 - Distribuição do percentual dos produtos químicos selecionados para este estudo, segundo a existência de informações toxicológicas nas fontes pesquisadas.

duto. Isto pode impedir o estabelecimento de limites biológicos e índices de exposição ocupacional e do estabelecimento da Ingesta Diária Aceitável. Em conseqüência, as empresas ficam sem informações adequadas para estabelecer programas preventivos para os seus trabalhadores e para a comunidade local. Além disso, a falta deste tipo de informação impede que empresas e governos estabeleçam condutas para a utilização segura de um produto químico ou para atender a emergências advindas de acidentes com esse produto, sejam em situações ocupacionais ou não.

Também como exemplo, a falta de informações relativas à genotoxicidade, mutagenicidade ou carcinogenicidade relacionadas aos produtos químicos gera duas preocupações básicas: as mutações em células germinativas podem causar aumento da incidência de doenças genéticas para as gerações futuras; e as mutações em células somáticas podem levar ao crescimento de tecido geneticamente alterado, com o desenvolvimento de doenças, incluindo o câncer. A primeira diz respeito, principalmente, ao futuro do potencial humano de um país. A segunda está associada com a queda na qualidade de vida das populações expostas e com os custos envolvidos para o tratamento de doenças. Dessa forma, é imprescindível tentar investigar, em laboratório, o quanto antes, quais produtos químicos possuem a capacidade de provocar danos ao material genético das células, evitando basear-se apenas em estudos epidemiológicos, que não são preventivos e não protegem os indivíduos que estão ou já foram expostos a um produto químico causador de mutações celulares.

Ainda nessa linha, estudos sobre toxicidade para a reprodução humana ou sobre a teratogenicidade de produtos químicos são estratégicos para um país, pois também dizem respeito à saúde das gerações futuras. Alguns produtos químicos ou seus metabólitos podem causar danos irreversíveis ao sistema reprodutivo masculino e feminino dos seres humanos, após uma ou várias exposições a estes produtos. Podem agir sobre o sistema reprodutivo de diversas formas, influenciando as funções normais das gônadas, os eventos envolvidos no ciclo menstrual, os mecanismos de concepção, de gestação, o parto e a lactação. Podem, por exemplo: alterar a produção dos hormônios responsáveis pelo controle bioquímico do sistema reprodutivo; alterar a produção de enzimas que controlam a meia-vida destes hormônios; danificar as membranas plasmáticas das células germinativas ou afetar a divisão celular dessas células com mutações genéticas ou aberrações cromossômicas. Além disso, alguns produtos químicos também podem induzir alterações no desenvolvimento normal dos seres humanos durante a concepção e o nascimento, gerando morte, disfunções biológicas pósnatal e anomalias morfológicas. Em conclusão, a falta destes tipos de informação também pode impedir a geração de programas preventivos, voltados para a saúde das populações brasileiras, atuais e futuras. 
TABELA IV - Nome dos produtos químicos excluídos da lista dos 150 produtos químicos selecionados para este estudo, por terem sido incluídos nos programas USEPA, ICCA ou OECD

\begin{tabular}{|c|c|c|}
\hline$\overline{\text { Número CAS }}$ & Nome do Produto Químico & $\begin{array}{l}\text { Motivo de Exclusão da Lista } \\
\text { de } 150 \text { Produtos Químicos }\end{array}$ \\
\hline $50-99-7$ & Glicose & $\begin{array}{l}\text { Produto de baixa prioridade de investigação, } \\
\text { na OECD }\end{array}$ \\
\hline $69-65-8$ & Manitol (Manita) & $\begin{array}{l}\text { Produto de baixa prioridade de investigação, } \\
\text { na OECD }\end{array}$ \\
\hline $124-38-9$ & Dióxido de carbono (Gás carbônico liquefeito) & $\begin{array}{l}\text { Produto de baixa prioridade de investigação, } \\
\text { na OECD }\end{array}$ \\
\hline $138-86-3$ & Limoneno & Foi incluído no programa da USEPA \\
\hline $1344-00-9$ & $\begin{array}{l}\text { Sílico-aluminato de sódio (silicato duplo } \\
\text { de alumínio e sódio) }\end{array}$ & $\begin{array}{l}\text { Produto de baixa prioridade de investigação, } \\
\text { na OECD }\end{array}$ \\
\hline $7440-37-1$ & Argônio & $\begin{array}{l}\text { Produto de baixa prioridade de investigação, } \\
\text { na OECD }\end{array}$ \\
\hline $7446-09-5$ & Dióxido de enxofre & Foi incluído no programa da USEPA \\
\hline 7446-11-9 & Trióxido de enxofre(Anidrido sulfúrico) & Foi incluído no programa da USEPA \\
\hline $7631-86-9$ & Dióxido de silício (Anidrido silícico) & Foi incluído no programa da USEPA \\
\hline $7664-38-2$ & Ácido fosfórico (Ácido orto-fosfórico) & Foi incluído no programa da USEPA \\
\hline $7722-76-1$ & Fosfato de amônio & Foi incluído no programa da USEPA \\
\hline $7727-37-9$ & Nitrogênio & $\begin{array}{l}\text { Produto de baixa prioridade de investigação, } \\
\text { na OECD }\end{array}$ \\
\hline $7775-09-9$ & Clorato de sódio & Foi incluído no programa da USEPA \\
\hline $7782-44-7$ & Oxigênio & Produto de baixa prioridade de investigação \\
\hline $7783-28-0$ & $\begin{array}{l}\text { Fosfato de Diamônio } \\
\text { (DAP; hidrogeno ortofosfato de diamônio) }\end{array}$ & Foi incluído no programa da USEPA \\
\hline $7790-94-5$ & Ácido clorossulfônico (Ácido clorossulfúrico ) & Foi incluído no programa da OECD \\
\hline $10124-37-5$ & Nitrato de cálcio & Foi incluído no programa da OECD \\
\hline $13463-67-7$ & Dióxido de titânio & Foi incluído no programa da OECD \\
\hline $112926-00-8$ & Dióxido de silício (sílica-gel) & $\begin{array}{l}\text { Produto de baixa prioridade de investigação, } \\
\text { na OECD }\end{array}$ \\
\hline
\end{tabular}

Além dos riscos para o homem, produtos químicos também podem apresentar riscos para as riquezas naturais de um país.

Os ensaios relacionados com a capacidade dos produtos químicos causarem efeitos nocivos nas populações das diversas espécies, além do homem, são fundamentais para a avaliação prévia de impactos ambientais e favorecem o estabelecimento de programas adequados para a proteção do meio ambiente e de suas populações. Por sua vez, os estudos que visam investigar a interação, distribuição e mecanismos de remoção de produtos químicos do ambiente são fundamentais nos programas de avaliações e gerenciamento de risco desses produtos. Um bom exemplo da importância destes estudos pode ser dado pela observação do comportamento no ambiente dos produtos químicos orgânicos persistentes ( $P O P S)$, que não são facilmente degradados ou hidrolisados, e tendem a ser transportados para regiões distantes daquelas onde ocorreu a contaminação ambiental. Por outro lado, não conhecer os riscos toxicológicos de um produto pode resultar em ações inconseqüentes por parte de seus fabricantes e usuários e gerar acidentes ambientais, com perda de recursos naturais do país e aumento das chances de exposição do homem a um produto químico nocivo para a sua saúde. Em suma, todos os dados toxicológicos pesquisados neste estudo são fundamentais para o estabelecimento de programas adequados de proteção do meio ambiente ou para auxiliar programas que visam remediar acidentes ambientais. Outro fator não menos 
TABELA V - Nome dos produtos químicos selecionados, com seus respectivos números $C A S$ e algumas formas de utilização.

\begin{tabular}{|c|c|c|}
\hline Número CAS & Nome do Produto Químico & Utilização do Produto Químico \\
\hline $50-56-6$ & Oxitocina & Produtos farmacêuticos e veterinários \\
\hline $50-70-4$ & D-Sorbitol & Produtos alimentícios, dentifrícios e produtos farmacêuticos \\
\hline $50-78-2$ & Ácido acetilsalicílico & Produtos farmacêuticos \\
\hline $52-68-6$ & Triclorfon & Defensivos agrícolas \\
\hline $56-86-0$ & Ácido glutâmico & Produtos alimentícios e farmacêuticos \\
\hline $56-87-1$ & Lisina & Produtos para ração animal \\
\hline $67-43-6$ & Ácido dietileno triamino pentacético & $\begin{array}{l}\text { Produtos auxiliares têxteis, couro, sabão e sabonetes e } \\
\text { produtos para tratamento de água }\end{array}$ \\
\hline $72-17-3$ & Lactato de sódio & Produtos alimentícios, farmacêuticos e cosméticos \\
\hline 77-94-1 & Citrato de tributila & Plásticos \\
\hline $80-53-5$ & Terpinol & Produtos de perfumaria e produtos farmacêuticos \\
\hline $87-20-7$ & Salicilato de isoamila & Cosméticos \\
\hline $87-69-4$ & Ácido tartárico & $\begin{array}{l}\text { Produtos auxiliares têxteis, cerâmicas, produtos para } \\
\text { galvanoplastia e produtos para fotografia }\end{array}$ \\
\hline $98-67-9$ & $\begin{array}{l}\text { Ácido fenolssulfônico } \\
\text { (Ácido sulfocarbólico) }\end{array}$ & Galvanoplastia \\
\hline $102-36-3$ & 3,4-Diclorofenilisocianato & Defensivos agrícolas \\
\hline $103-90-2$ & Paracetamol (acetaminofeno) & Produtos farmacêuticos \\
\hline $106-23-0$ & Citronelol & Produtos de perfumaria \\
\hline $115-29-7$ & Endossulfan & Defensivos agrícolas \\
\hline $115-32-2$ & Dicofol & Defensivos agrícolas \\
\hline $118-96-7$ & 2,4,6-Trinitrotolueno (TNT) & Explosivos \\
\hline $120-18-3$ & Ácido 2-naftalenossulfônico & Produtos para Couro e galvanoplastia \\
\hline $122-34-9$ & Simazina & Herbicida \\
\hline $123-51-3$ & $\begin{array}{l}\text { Álcool Isoamílico } \\
\text { (Álcool amílico; isopentanol; pentanol) }\end{array}$ & $\begin{array}{l}\text { Cosméticos, solventes, produtos para perfumaria, tintas e } \\
\text { vernizes. }\end{array}$ \\
\hline $123-92-2$ & $\begin{array}{l}\text { Acetato de isoamila } \\
\text { (Acetato de amila; acetato de isopentila) }\end{array}$ & Produtos para perfumaria, solventes, tintas e vernizes \\
\hline $124-11-8$ & Noneno & Solventes \\
\hline $125-12-2$ & Acetato de isobornila & Produtos alimentícios e perfumaria \\
\hline $133-06-2$ & Captan & $\begin{array}{l}\text { Tintas, plásticos, sabão e sabonetes, couro, papel e } \\
\text { cosméticos. }\end{array}$ \\
\hline $134-32-7$ & 1-Naftilamina (alfa),2-naftilamina (beta) & Corantes e herbicidas \\
\hline $141-22-0$ & Ácido ricinoléico & Produtos químicos para têxteis \\
\hline $142-31-4$ & Octilsulfato de sódio & Detergentes e produtos químicos para têxteis \\
\hline $142-59-6$ & $\begin{array}{l}\text { Etileno-bis-Ditiocarbamato de sódio } \\
\text { (Nabam) }\end{array}$ & Defensivos agrícolas \\
\hline $153-18-4$ & Rutina & Produtos farmacêuticos e alimentícios \\
\hline $298-00-0$ & Metil paration & Inseticidas \\
\hline 298-04-4 & Dissulfoton & Inseticidas \\
\hline $304-59-6$ & Tartarato de potássio e sódio & Produtos alimentícios, farmacêuticos e galvanoplastia \\
\hline $471-34-1$ & Carbonato de cálcio precipitado & $\begin{array}{l}\text { Papel e celulose, plásticos, cosméticos, tintas, borrachas e } \\
\text { dentifrícios }\end{array}$ \\
\hline $554-13-2$ & Carbonato de lítio & Produtos farmacêuticos e intermediários químicos \\
\hline $557-34-6$ & Acetato de zinco & Produtos alimentícios e farmacêuticos \\
\hline $593-70-4$ & $\begin{array}{l}\text { Clorofluormetano } \\
\text { (CFC; cloro-fluorcarbonos) }\end{array}$ & Aerossóis \\
\hline
\end{tabular}


TABELA V - continuação

\begin{tabular}{|c|c|c|}
\hline$\overline{\text { Número CAS }}$ & Nome do Produto Químico & Utilização do Produto Químico \\
\hline $709-98-8$ & Propanil & Defensivos agrícolas \\
\hline $814-80-2$ & Lactato de cálcio & Preservante para produtos alimentícios e dentifrícios \\
\hline $834-12-8$ & Ametrina & Herbicida \\
\hline $1071-83-6$ & Glifosato & Defensivos agrícolas \\
\hline $1309-60-0$ & $\begin{array}{l}\text { Óxido de chumbo } \\
\text { (Protóxido de chumbo) }\end{array}$ & Pigmentos \\
\hline $1310-02-7$ & Fluossilicato de sódio & $\begin{array}{l}\text { Inseticidas, rodenticida, colas, couro preservante } \\
\text { de madeira, repelente }\end{array}$ \\
\hline $1310-65-2$ & Hidróxido de lítio & Lubrificantes \\
\hline $1344-43-0$ & $\begin{array}{l}\text { Óxido manganoso } \\
\text { (Monóxido de manganês) }\end{array}$ & $\begin{array}{l}\text { Pigmento têxtil, cerâmica, tintas, fertilizantes e produtos } \\
\text { alimentícios }\end{array}$ \\
\hline $1344-67-8$ & Oxicloreto de cobre & Defensivos agrícolas \\
\hline $1345-05-7$ & Litopônio & Pigmento para tintas, papel e couro \\
\hline $1582-09-8$ & Trifluralina & Defensivos agrícolas \\
\hline $1863-63-4$ & Benzoato de amônio & Produtos farmacêuticos \\
\hline 2008-39-1 & $\begin{array}{l}\text { 2,4-Diclorofenoxiacetato } \\
\text { de dimetilamina }\end{array}$ & Herbicidas \\
\hline $2064-80-4$ & Azelato de dioctila (DOZ) & Plásticos \\
\hline $2312-35-8$ & Propargite & Defensivos agrícolas \\
\hline $2921-88-2$ & Cloropirifos & Defensivos agrícolas \\
\hline $2921-92-8$ & $\begin{array}{l}\text { 2-Etil-2-(Hidroximetil) } \\
\text { propano-1,3-diol (trinitrato) }\end{array}$ & Vaso dilatador \\
\hline $3344-18-1$ & Citrato de magnésio & Produtos farmacêuticos \\
\hline $3734-33-6$ & Denatônio, benzoato & Cosméticos, defensivos agrícolas e produtos veterinários \\
\hline $3811-04-9$ & Clorato de potássio & Explosivos, têxtil, desinfetantes e alvejantes \\
\hline $4405-13-4$ & Glioxal & Resinas têxteis \\
\hline $4685-14-7$ & Paraquat & Herbicidas \\
\hline $5464-28-8$ & Gliceroformal & Produtos farmacêuticos \\
\hline $5907-38-0$ & Dipirona & Produtos farmacêuticos \\
\hline $6259-76-3$ & Salicilato de hexila & Produtos farmacêuticos \\
\hline $7320-34-5$ & Pirofosfato tetrapotássico & Sabões e detergentes \\
\hline $7440-23-5$ & Sódio, metal alcalino & Reações químicas diversas \\
\hline $7722-88-5$ & Pirofosfato de sódio & Sabões e detergentes, galvanoplastia, têxtil e alimentício \\
\hline $7758-05-6$ & Iodato de potássio & Alimentação humana e animal \\
\hline $7758-16-9$ & Pirofosfato ácido de sódio & Sabões e detergentes, alimentício e galvanoplastia \\
\hline $7758-29-4$ & $\begin{array}{l}\text { Tripolifosfato de sódio } \\
\text { (Trifosfato de sódio) }\end{array}$ & $\begin{array}{l}\text { Sabões e detergentes, têxtil, papel e celulose, tratamento de } \\
\text { água e metais }\end{array}$ \\
\hline $7778-39-4$ & Ácido arsênico & $\begin{array}{l}\text { Tratamento de madeira, esterilizante de solo, manufatura de } \\
\text { vidro }\end{array}$ \\
\hline $7782-44-7$ & Oxigênio & $\begin{array}{l}\text { Produtos para siderurgia, metalurgia, hospital, papel e } \\
\text { celulose, tratamento de efluentes e fabricação de vidros }\end{array}$ \\
\hline $7787-59-9$ & Oxicloreto de bismuto & Fabricação de abrasivos, cerâmica e refratários \\
\hline $8001-54-5$ & Cloreto de benzalcônio & $\begin{array}{l}\text { Produtos farmacêuticos, cosméticos, domossanitários, } \\
\text { alimentícios, sabões e detergentes }\end{array}$ \\
\hline $8012-95-1$ & $\begin{array}{l}\text { Óleo mineral branco } \\
\text { (Óleos de parafina) }\end{array}$ & $\begin{array}{l}\text { Produtos farmacêuticos, cosméticos, alimentícios e } \\
\text { veterinários }\end{array}$ \\
\hline $8014-95-7$ & Ácido sulfúrico fumegante & Defensivos agrícolas \\
\hline $9000-92-4$ & Alfa-amilase (Aspergillus oryzae) & Sabões e detergentes \\
\hline $9001-62-1$ & Lipase & Sabões e detergentes \\
\hline
\end{tabular}


TABELA V - continuação

\begin{tabular}{|c|c|c|}
\hline Número CAS & Nome do Produto Químico & Utilização do Produto Químico \\
\hline $9002-86-2$ & Policloreto de vinila (PVC) & $\begin{array}{l}\text { Revestimento de fios e cabos, embalagens, calçados, } \\
\text { produtos automobilísticos e fabricação de mangueiras }\end{array}$ \\
\hline $9002-88-4$ & Polietileno & $\begin{array}{l}\text { Produtos para higiene e limpeza, alimentícios, sacolas, } \\
\text { utilidades domésticas, tubos e conexões }\end{array}$ \\
\hline $9002-89-5$ & Álcool polivinílico & $\begin{array}{l}\text { Resinas para têxteis, cosméticos, cerâmica, couro, papel e } \\
\text { fotográfico }\end{array}$ \\
\hline $9003-05-8$ & Poliacrilamida & $\begin{array}{l}\text { Fabricação de açúcar e álcool, efluentes e tratamento de } \\
\text { água }\end{array}$ \\
\hline $9003-07-0$ & Polipropileno & Produtos automobilísticos, alimentícios e fibras \\
\hline $9003-17-2$ & Polibutadieno (Poli-(1,3-butadieno)) & Colas, adesivos, tintas e vernizes \\
\hline $9003-20-7$ & Acetato de polivinila (PVAC) & Colas e adesivos, tintas, vernizes e têxtil \\
\hline $9004-35-7$ & Acetato de celulose & $\begin{array}{l}\text { Fibras, filmes fotográficos, termoplásticos, fitas magnéticas } \\
\text { e membranas osmóticas }\end{array}$ \\
\hline $9004-62-0$ & Hidroxietilcelulose & Construção civil e tintas e vernizes \\
\hline $9004-70-0$ & Nitrocelulose (Nitrato de celulose) & Produtos para têxteis \\
\hline $9005-25-8$ & Amido & $\begin{array}{l}\text { Produtos alimentícios, têxteis, farmacêuticos, papel e } \\
\text { celulose e setor petrolífero }\end{array}$ \\
\hline $9005-46-3$ & Caseinato de sódio & Produtos alimentícios \\
\hline $9011-14-7$ & Polimetacrilato de metila & Construção civil e peças técnicas \\
\hline $9012-54-8$ & Celulase & Produtos alimentícios e têxteis \\
\hline $9036-19-5$ & Octilfenol etoxilado & Defensivos agrícolas e resinas sintéticas \\
\hline $9048-90-2$ & Poliuretano (Resina de poliuretano) & $\begin{array}{l}\text { Colas, adesivos, tintas e vernizes, calçados, automobilismo, } \\
\text { telecomunicação, eletro-eletrônico }\end{array}$ \\
\hline $10025-84-0$ & Cloreto de lantânio & Preparação de metais \\
\hline $10026-24-1$ & Sulfato de cobalto & Produtos para alimentação animal \\
\hline $10101-52-7$ & Silicato de zircônio & Abrasivos, silicones e borrachas de silicone \\
\hline $10101-53-8$ & Sulfato de cromo (Cromosal) & Tintas e vernizes e cerâmica \\
\hline $10192-30-0$ & Bissulfito de amônio & $\begin{array}{l}\text { Têxtil, cerâmica, papel e celulose, tratamento de água, } \\
\text { petrolífero }\end{array}$ \\
\hline $10265-92-6$ & Metamidofós & Defensivos agrícolas \\
\hline 10294-56-1 & Ácido fosfônico (Ácido fosforoso) & Agente químico de redução e sais de fósforo \\
\hline $10326-21-3$ & Cloreto de magnésio & $\begin{array}{l}\text { Desinfetantes, extintores de incêndio, cerâmica, têxtil e } \\
\text { produção de papel }\end{array}$ \\
\hline $10361-37-2$ & Cloreto de bário & Tratamento de metais, metalurgia e processos químicos \\
\hline $10377-60-3$ & Nitrato de magnésio & Fertilizantes \\
\hline $10421-48-4$ & Nitrato férrico & Produtos fotográficos \\
\hline $11138-49-1$ & Aluminato de sódio & Tratamento de água \\
\hline $12280-03-4$ & Octaborato de Sódio & Produtos farmacêuticos e fertilizantes \\
\hline $51218-45-2$ & Metolaclor & Herbicida \\
\hline $16871-71-9$ & Fluossilicato de zinco & Tratamento de metais e metalurgia \\
\hline 19210-06-1 & Dialquilditiofosfato de zinco & Aditivos para lubrificantes \\
\hline $20427-59-2$ & Hidróxido de cobre & Produtos farmacêuticos \\
\hline 20859-73-8 & Fosfeto de alumínio & Defensivos agrícolas \\
\hline 22831-39-6 & Silicato de magnesio & $\begin{array}{l}\text { Carga para borrachas, cerâmica, vidros, refratários, papeis } \\
\text { e secante de tintas }\end{array}$ \\
\hline $23564-05-8$ & Tiofanato-metila & Fungicidas \\
\hline 25038-54-4 & $\begin{array}{l}\text { Nylon "6" } \\
\text { (Poliamida “6"; policaprolactama) }\end{array}$ & Pneus, embalagens, fibras, peças técnicas \\
\hline $25038-59-9$ & Tereftalato de polietileno (PET) & Produtos têxteis, embalagens e fitas cassete \\
\hline
\end{tabular}


TABELA V - continuação

\begin{tabular}{|c|c|c|}
\hline$\overline{\text { Número CAS }}$ & Nome do Produto Químico & Utilização do Produto Químico \\
\hline $25190-06-1$ & Politetrametilenoeterglicol & Produtos de poliuretano \\
\hline $25322-68-3$ & Polietilenoglicol (PEG) & $\begin{array}{l}\text { Produtos plastificantes, amaciantes, polidores, lubrificantes, } \\
\text { cosméticos, produtos farmacêuticos e aditivos para } \\
\text { comida animal. }\end{array}$ \\
\hline $25322-69-4$ & Polipropilenoglicol & Poliuretanos \\
\hline $30525-89-4$ & Paraformaldeido & $\begin{array}{l}\text { Fungicidas, bactericidas, desinfetantes, adesivos e cremes } \\
\text { contraceptivos. }\end{array}$ \\
\hline 30560-19-1 & $\begin{array}{l}\text { Acefato } \\
\text { (Éster do ácido acetilfosforoamidotióico) }\end{array}$ & $\begin{array}{l}\ldots \\
\text { Inseticidas }\end{array}$ \\
\hline $37953-05-2$ & Ácido cumenossulfônico & $\ldots$ \\
\hline $40487-42-1$ & Pendimetalina & Herbicida \\
\hline $51022-70-9$ & Salbutamol, sulfato & Medicamentos \\
\hline $52628-25-8$ & $\begin{array}{l}\text { Cloreto de zinco e amônio } \\
\text { (Cloreto de zinco amoniacal) }\end{array}$ & Galvanoplastia \\
\hline $54965-21-8$ & Albendazol & Produtos veterinário e farmacêutico \\
\hline 55134-13-9 & Narasina & Herbicida \\
\hline $55285-14-8$ & Carbosulfan & Defensivos \\
\hline $61789-96-6$ & Borracha de butadieno-estireno (SBR) & Pneus, calçados e peças técnicas \\
\hline $64365-11-3$ & Carvão ativado & $\begin{array}{l}\text { Alimentício, farmacêutico, tratamento de água e efluentes, } \\
\text { defensivos agrícolas galvanoplastia e processos químicos }\end{array}$ \\
\hline $66357-35-5$ & Ranitidina & Produtos farmacêuticos \\
\hline $74811-65-7$ & Croscarmelose sódica & Produtos farmacêuticos \\
\hline $81591-81-3$ & Sulfosato & Herbicidas \\
\hline
\end{tabular}

importante para o país é a existência de índices especiais, em bolsas de valores, onde empresas com programas ambientais adequados podem ter suas ações valorizadas por meio desses índices econômicos.

Em 2005, doze produtos químicos da lista de 131 produtos constantes da Tabela $\mathrm{V}$, ou seja, que não possuíam nenhuma informação toxicológica em 2000 (Tabela IV), foram novamente pesquisados na base de dados da Biblioteca Nacional de Medicina dos Estados Unidos e verificouse que nenhuma informação foi incluída e, portanto, elas continuam sem, pelo menos, um dos nove tipos de informações toxicológicas pesquisadas nesse estudo (Tabela VI).

Em conclusão a este estudo, as informações geradas foram suficientes para: reconhecer a impossibilidade de elaborar o inventário de todos os produtos químicos utilizados no Brasil, usando as informações publicamente disponíveis no país; elaborar um inventário de parte dos produtos químicos utilizados em larga escala no Brasil, com dados científicos suficientes para uma identificação inequívoca de seus componentes; conhecer os produtos químicos utilizados no Brasil, que estão sendo investigadas toxicologicmente por programas de competência reconhecida pala comunidade científica internacional (OECD, EPA e ICCA); conhecer os produtos químicos utilizados no Brasil, que já possuem informações suficientes para suportar estudos de avaliação do risco; e avaliar a existência de informações toxicológicas relativas à identificação de perigo e comportamento no ambiente de 131 produtos químicos utilizados em larga escala no Brasil.

TABELA VI - Nome dos produtos químicos selecionados para este estudo, com seus respectivos números $C A S$ que não possuem qualquer dos nove tipos de informações toxicológicas abordadas neste estudo

\begin{tabular}{|c|c|}
\hline Número CAS & Nome do Produto Químico \\
\hline $80-53-5$ & Terpinol \\
\hline $2064-80-4$ & Azelato de dioctila (DOZ) \\
\hline $2921-92-8$ & $\begin{array}{l}\text { 2-Etil-2-(hidroximetil)propano-1,3-diol } \\
\text { (trinitrato) }\end{array}$ \\
\hline $10101-52-7$ & Silicato de zircônio \\
\hline $10192-30-0$ & Bissulfito de amônio \\
\hline $10377-60-3$ & Nitrato de magnésio \\
\hline $11138-49-1$ & Aluminato de sódio \\
\hline $22831-39-6$ & Silicato de magnésio \\
\hline $37953-05-2$ & Ácido cumenossulfônico \\
\hline $52628-25-8$ & $\begin{array}{l}\text { Cloreto de zinco e amônio (Cloreto de } \\
\text { zinco amoniacal) }\end{array}$ \\
\hline $74811-65-7$ & Croscarmelose sódica \\
\hline $9004-62-0$ & Hidroxietilcelulose \\
\hline
\end{tabular}




\section{ABSTRACT \\ Evaluation of the availability of toxicological information of chemicals used in wide scale in Brazil}

This study had as purpose to survey the existence of nine types of toxicological information on chemical products that are being used in Brazil, in higher or equal amounts of 500 tons per year, restricted to those products whose inquiries are not being made by recognized entities in the international scientific community. As result, the study showed that in sampling of 461 chemical products used in wide scale in Brazil, only eighteen of these products had the nine types of toxicological information evaluated. Also it was demonstrated that twelve chemical products did not had any toxicological information, disabling their risk evaluation.

UNITERMS: Risk assessment. Hazard identification. Chemical products/Toxicological data. Social responsibility. Chemical safety.

\section{REFERÊNCIAS BIBLIOGRÁFICAS}

ABIQUIM - ASSOCIAÇÃO BRASILEIRA DA INDÚSTRIA QUÍMICA. Programa atuação responsável, 1992. Disponível em: <http:// www.abiquim.org.br> Acesso em/: 18 abr.2000.

ANUÁRIO DA INDÚSTRIA QUÍMICA BRASILEIRA. São Paulo: ABIQUIM - Associação Brasileira da Indústria Química, v.26, 2000.278p.

BRASIL. Portaria N. 319, de 27 de novembro de 2000. Cria a COPASQ - Comissão Coordenadora do Plano de Ação para a Segurança Química e dá outras providências. Diário Oficial da República Federativa do Brasil, Brasília. n. 1, p. 28 e 29, 02 jan. 2001. Seção 1.

EDF- ENVIRONMENTAL DEFENSE FUND. Toxic ignorance, 1997. Disponível em: <http:// www.environmentaldefense.org> Acesso em/: 18 abr. 2000.

EPA - ENVIRONMENTAL PROTECTION AGENCY. (Chemical righ-to-know initiative, 1998. Disponivel em: $<$ http://www.epa.gov/opptintr/chemtest/hazchem.htm> Acesso em/: 18 abr. 2000.
EPA - ENVIRONMENTAL PROTECTION AGENCY. Chemrtk HPV challenger program chemical list, 2000. Disponível em: <http://www.epa.gov/chemrtk/ hpvchmlt.htm $>$ Acesso em/:. 11 jun. 2000.

EPA - ENVIRONMENTAL PROTECTION AGENCY. AQUIRE - Aquatic information retrieval data base, 1998d. Disponivel em: <http://www.epa.gov/med/ aquire.html $>$ Acesso em. 11 jun. 2000.

EPA - ENVIRONMENTAL PROTECTION AGENCY. AQUIRE - Aquatic information retrieval data base, 1998d. Disponivel em: <http://www.epa.gov/med/ aquire.html $>$ Acesso em. 01 mar. 2005.

EPA - ENVIRONMENTAL PROTECTION AGENCY. Chemical hazard data availability study, 1998a. Disponível em: $<$ http://www.epa.gov/chemrtk>Acesso em 18 abr. 2000.

EPA - ENVIRONMENTAL PROTECTION AGENCY. Chemical hazard data availability study. Disponível em: $<$ http://www.epa.gov/chemrtk> Acesso em 01 mar. 2005.

EPA - ENVIRONMENTAL PROTECTION AGENCY. Chemical hazard data availability study: appendix II, 1998c. Disponível em: <http://www.epa.gov/chemrtk> Acesso em 31 set. 2001.

EPA - ENVIRONMENTAL PROTECTION AGENCY. Chemical hazard data availability study: appendix II. Disponível em: <http://www.epa.gov/chemrtk>Acesso em 01 mar. 2005.

EPA - ENVIRONMENTAL PROTECTION AGENCY. Phytotox data base, 1998e. Disponível em: <http:// www.epa.gov/med/phytotox.html $>$ Acesso em. 11 jun. 2000.

EPA - ENVIRONMENTAL PROTECTION AGENCY. Phytotox data base. Disponível em: <http:// www.epa.gov/med/phytotox.html $>$ Acesso em. 01 mar. 2005.

FAUSTMAM, E. M; OMENN, G.S. Avaliação de risco. In: KLAASSEM, C. D. Cassarett \& Doull's toxicologythe basic science of poison. New York: Mc Graw-Hill, 1996. p. 75-88.

GUIA DA INDÚSTRIA QUÍMICA BRASILEIRA. São Paulo: ABIQUIM - Associação Brasileira da Indústria Química, 2v.15, 2001.404 p. 
GUIA DA INDÚSTRIA QUÍMICA BRASILEIRA. São Paulo: ABIQUIM - Associação Brasileira da Indústria Química, ano IVX, 2005. 508p.

ICCA - INTERNATIONAL COUNCIL OF CHEMICAL ASSOCIATION. Global initiative on high production volume (HPV) chemicals, 1999. Disponível em/: $<\mathrm{http}$ // /www.iccahpv.com> Acesso em/: 06 jun. 2001.

ICF KAISER INTERNATIONAL. Public availability of SIDS - related testing data for U.S. High production volume chemicals. Fairfax: CMA - Chemical manufacture association, 1998.

IFCS - INTERGOVERNAMENTAL FORUM ON CHEMICAL SAFETY. Involvement of non-OECD countries in the OECD High Production Volume Chemical Programme, 2000. Disponível em/: < http:// www.who.int/ifcs/forum3/docs.html > Acesso em/: 22.jan.2002.

IUPAC - INTERNATIONAL UNION OF PURE AND APPLIED CHEMISTRY. Disponivel em/: < http:// iupac.chemsoc.org/> Acesso em/: 01 fev. 2002.

MINISTÉRIO DO MEIO AMBIENTE. Agenda 21, 1992. Disponível em/::<http://www.mma.gov.br $>$ Acesso em/ : 19 nov. 2001.

NLM - NATIONAL LIBRARY OF MEDICINE. CCRIS Chemical Carcinogenesis Research Information System. Disponível em: < http://toxnet.nlm.nih.gov > Acesso em 22 jan. 2002.

NLM - NATIONAL LIBRARY OF MEDICINE. CCRIS Chemical Carcinogenesis Research Information System. Disponível em: < http://toxnet.nlm.nih.gov > Acesso em 01 mar. 2005.

NLM - NATIONAL LIBRARY OF MEDICINE. ChemIDplus, 2002. Disponível em: < http:// toxnet.nlm.nih.gov $>$ Acesso em 22 jan. 2002.

NLM - NATIONAL LIBRARY OF MEDICINE. ChemIDplus, . Disponível em: $<$ http://toxnet.nlm.nih.gov $>$ Acesso em 01 mar. 2005.

NLM - NATIONAL LIBRARY OF MEDICINE. EMIC Environmental mutagen information center, 1998g. Disponível em: < http://toxnet.nlm.nih.gov> Acesso em 22 jan. 2002.
NLM - NATIONAL LIBRARY OF MEDICINE. EMIC Environmental mutagen information center. Disponível em: < http://toxnet.nlm.nih.gov>Acesso em 01 mar. 2005.

NLM - NATIONAL LIBRARY OF MEDICINE. ETIC Environmental teratology information center, $1998 \mathrm{~h}$. Disponível em: < http://toxnet.nlm.nih.gov > Acesso em 22 jan. 2002.

NLM - NATIONAL LIBRARY OF MEDICINE. ETIC Environmental teratology information center Disponível em: < http://toxnet.nlm.nih.gov > Acesso em 01 mar. 2002.

NLM - NATIONAL LIBRARY OF MEDICINE. GENETOX, 1998f. Disponível em: < http://toxnet.nlm.nih.gov> Acesso em 22 jan. 2002.

NLM - NATIONAL LIBRARY OF MEDICINE. GENETOX. Disponível em: $<$ http://toxnet.nlm.nih.gov $>$ Acesso em 01 mar. 2002.

NLM - NATIONAL LIBRARY OF MEDICINE. IRIS Integrated Risk Information System, 1998d. Disponível em: < http://toxnet.nlm.nih.gov > Acesso em 22 jan. 2002.

NLM - NATIONAL LIBRARY OF MEDICINE. IRIS Integrated Risk Information System, 1998d. Disponível em: < http://toxnet.nlm.nih.gov>Acesso em 01 mar. 2005.

NLM - NATIONAL LIBRARY OF MEDICINE. RTECS Registry of toxic effects of chemical substances, 1998b. Disponível em: < http://toxnet.nlm.nih.gov > Acesso em 22 jan. 2002.

NLM - NATIONAL LIBRARY OF MEDICINE. SIS Specialized information service, 1998a. Disponível em: $<$ http://sis.nlm.nih.gov > Acesso em 22 jan. 2002.

NLM - NATIONAL LIBRARY OF MEDICINE. SIS Specialized information service. Disponível em: $<$ http:/ /sis.nlm.nih.gov > Acesso em 01 mar. 2005.

NLM - NATIONAL LIBRARY OF MEDICINE. TOXILINE - Toxicology literature Online, 1998c. Disponível em: < http://esc.syrres.com/efdb/ TSCATS.htm > Acesso em 22 jan. 2002.

NLM - NATIONAL LIBRARY OF MEDICINE. TOXILINE - Toxicology literature Online. Disponível em: $<$ http://esc.syrres.com/efdb/TSCATS.htm $>$ Acesso em 01 mar. 2005. 
OECD - ORGANIZATION FOR ECONOMICCOOPERATION AND DEVELOPMENT. Co-Operating on the investigation of existing chemicals, 1991. Disponível em/: $<$ http://www.oecd.org $>$ Acesso em 24 nov. 2000.

OECD - ORGANIZATION FOR ECONOMICCOOPERATION AND DEVELOPMENT. Co-Operating on the investigation of existing chemicals, 1991. Disponível em/: $<$ http://www.oecd.org $>$ Acesso em 01 mar. 2005.

UNEP - UNITED NATIONS ENVIRONMENT PROGRAMME. UNEP chemical. Disponível em/: < http://irptc.unep.ch/irptc > Acesso em/: 09 ago. 2001.

UNEP - UNITED NATIONS ENVIRONMENT PROGRAMME. UNEP chemical. Disponível em/: < http://www.chem.unep.ch/irptc/sids/OECDSIDS/ sidspub.html $>$ Acesso em/: 09 jul. 2005 ..

[WHO] WORLD HEALTH ORGANIZATION. 2,4 Dichlorophenoxyacetic acid. Geneva: WHO, 1984. (Environmental Health Criteria, 29)
[WHO] WORLD HEALTH ORGANIZATION. Endosulfan . Geneva: WHO, 1984. (Environmental Health Criteria, 40)

[WHO] WORLD HEALTH ORGANIZATION. Dithiocarbamate pesticides, ethylenethiourea, and propylenethiourea: a general introduction. Geneva: WHO, 1988. (Environmental Health Criteria, 78)

[WHO] WORLD HEALTH ORGANIZATION. 2,4 Dichlorophenoxyacetic acid. Environmental Aspects . Geneva: WHO, 1989. (Environmental Health Criteria, 84)

[WHO] WORLD HEALTH ORGANIZATION. Triclorfon. Geneva: WHO, 1992. (Environmental Health Criteria, 132)

[WHO] WORLD HEALTH ORGANIZATION. Methyl parathion. Geneva: WHO, 1992. (Environmental Health Criteria, 145).

[WHO] WORLD HEALTH ORGANIZATION. Glyphosate. Geneva: WHO, 1994. (Environmental Health Criteria, 159).

Recebido para publicação em 01 de setembro de 2004. Aceito para publicação em 22 de agosto de 2005. 